\title{
The Impact of Using Blackboard on Student's Grades
}

\author{
https://doi.org/10.3991/ijim.v15i23.27711
}

\author{
Dalia Alshmasi ${ }^{(\bowtie)}$, Jawaher Alharbi, Nada Alhothly \\ Qassim University, Buraydah, Saudi Arabia \\ 362208371@qu. edu. sa
}

\begin{abstract}
The Learning Management System (LMS) is a core system that contributes to support e-learning, manage content, provide learning tools, and facilitate communication between students and teachers. This project aims to measure the impact of Blackboard-based e-learning use. We measure the effect of blackboard use on male students by comparing male and female students' degrees of online learning (online class preparation) and traditional (face-toface) learning at Qassim University, using statistical methods and data mining algorithms. We also develop A supportive tool that helps teachers manage some important tasks such as (student attendance, interaction, grades ... etc.). This tool will take student information and push automatic notifications to all concerned people via SMS.
\end{abstract}

Keywords-e-learning, learning management systems, blackboard, data mining, grades, flask framework, SMS, t-test, CNN

\section{Introduction}

Today, with the increase of mobile and digital devices, the use of technology has become fundamental in learning and education. E-learning contributes widely to develop countries and increase their growth. E-learning has arisen as a learning environment competitive with traditional learning. However, it can complement to the traditional learning as a blended learning. Blended learning is the integration of E-learning and traditional learning in one work environment to gain more knowledge and interaction [1]. In this project, we aim to analyze two datasets using Apriori Algorithm and Independent Sample T-Test which compares the relations between the two groups is statistically significant [2]. Apriori algorithm is one of the most common data mining algorithms to find the repeated set of elements from large data sets using the association rules [3]. The two datasets that involve in these tests are face-to-face and online courses' grades. We intend to illustrate the relationship between students' grades in online courses and students' grades in study face to face course. Then, extract relations and features for each type. Our datasets contain 1802 rows of students' online course grades. The faceto-face dataset also contains 618 rows. Each dataset contains five columns (ID number, semester works, Final Exam, Final Degree, and Gender). In Apriori Algorithm we exam the support between final exam and semester work for each student in face-to-face and online datasets [4]. After that, we conclude rules. In the Independent Sample T-Test, we aim to conduct comparisons between student grades in face-to-face courses and 
the same online courses. The first step is illustrating the implementation of the Apriori algorithm, then we illustrate the implementation of the independent t-test.

However, we implemented an SMS tool, using the Flask framework, through its depended on the Hi SMS company services to offer a web interface that enables the user to send and receive messages.

The following of this paper is organized as follows. The related work is analyzed in Section 2. The proposed work is explained in Section 3. Sections 4 shows the results and discussions. The experimental is presented in Section 5. Finally, conclusion is shown in Section 6

\section{Related work}

We applied many research and studies related to the use of LMS Bb and E-learning, for example, A study conducted at a UK university to evaluate the SMS service. Through an online questionnaire, it was applied to three categories of different departments. The research feedback offers a more structured way to strengthen the relation between teachers and students [5].

A study at King Saud University was applied using a questionnaire to measure the satisfaction of students and faculty members with the teaching and learning experience using learning management system $\mathrm{Bb}$. Most faculty and students expressed their satisfaction [6]. This study performed a comparison between two groups: face-to-face and distance learning, based on students' grades and the influence of demographics. They concluded that there was a clear connection between the regular use of $\mathrm{Bb}$ and higher grades of students [7]. A study conducted at King Saud University (2016) to describe the level of usability and accessibility of the $\mathrm{Bb}$. A questionnaire obtained a high percentage of the reliability of Findings $=0.8$. The findings demonstrated that many favors the use of $\mathrm{Bb}$ in learning [8].

However, a study at the University of Hail to evaluate the use of learning tools in the framework of the $\mathrm{Bb}$. Through a questionnaire to find out the position of faculty members on the use of $\mathrm{Bb} .80 \%$ of the participants agreed that $\mathrm{Bb}$ is an effective learning management system [9]. Further, another study conducted at King Khalid University finds the pros and cons of using $\mathrm{Bb}$ and blended learning and its impact on students by comparison between a paper test and an electronic test. The electronic test and the use of $\mathrm{Bb}$ in blended learning had positive results [10].

A university in the southeastern United States applied Blackboard to explore the experiences of instructors who used $\mathrm{Bb}$ with their traditional face-to-face courses. They found it improves communication and teaching methods in the classroom [11]. Another study at King Khalid University explains the effects of using inline to manage subjects in E-learning. They found that deep learning improves e-learning [12].

A study was applied at King Abdul-Aziz University to measure the effectiveness of $\mathrm{Bb}$ and the impact of formative assessment. The results summarized that most students are satisfied with the use of the $\mathrm{Bb}$. Also, it is possible to use formative assessment [13]. In this paper, he searches for the operations of classifying Arabic texts based on the textual content of the Internet. As data over the Internet increases as text, there is an increasing need to use algorithms that classify these scripts. To improve the results, text classification is used for (CNN) [14]. 
In [15] SMS was used. In our research, we will create a tool that sends short messages at the time of handing out assignments, and when students are deprived of the academic semester. These notifications connect students, teachers, and student affairs through the $\mathrm{Bb}$ at the Qassim University. In [9] [6], The satisfaction and use of faculty and students for $\mathrm{Bb}$ were measured through a questionnaire. In our research, we will use open questioning for teachers and students enrolled in online materials via the $\mathrm{Bb}$ to measure their satisfaction with its use.

In [7] [10], two groups were compared: face-to-face and distance learning based on grades, the study applied to a small sample. In our research, we will compare students' grades in the courses offer face-to-face and online based on a large sample of, students, and several colleges. In [14] and [12], inline and algorithms for classification Arabic texts are described. In our research, we will provide open-ended questioning in Arabic for instructors and students through online courses via $\mathrm{Bb}$ to measure their satisfaction. To analyze the Arabic text in open questioning and measure results, we will use CNN algorithms.

\section{Proposed work}

This system aims to discover the effect of using the Bb system on students' grades. In addition to developing an (SMS) tool to help support the Blackboard system used at Qassim University. By using, flask a mini web framework written in Python by Hi SMS service. Which serves the faculty members to manage some tasks such as (sending alerts to all students of the course and communicate with them) as well as sending automatic notifications to students without the need for the intervention of the professor (such as the students' attendance, their grades, their homework dates). Without the need for an Internet presence, via (SMS). The task of this tool is to take student information from the system and send notifications to all concerned persons (studentsfaculty members - head of the student affairs department and dean) at a time when the concerned person may be offline. We also strive to measure student and faculty satisfaction using $\mathrm{Bb}$ and available features, to find the opinions of students and faculty from several academic and technical aspects. As shown in Figure 1.

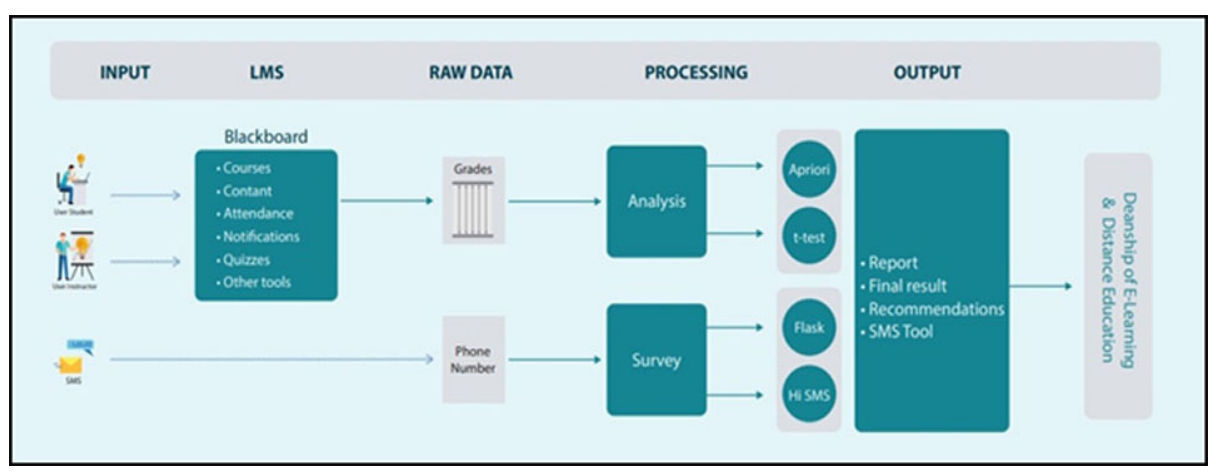

Fig. 1. I-Bb-LMS-SG model 


\section{$4 \quad$ Results and discussion}

We focus on students' data (grades) to analyze and compare them to reach results that can be used in the future to find out whether the courses taught online through the blackboard are better or the face-to-face courses. Regarding the SMS tool, data was first collected through a questionnaire to access personal data (which includes their phone numbers) for each of the students, teachers, and employees, and then include in the interface of the SMS tool to try it.

Data analysis methods. The students' grades (mid-term grades, final grades) were analyzed through an Apriori algorithm. Also, a t-test was used to compare the (total grade) grades for the students between the final grades of the online and face-to-face courses.

SMS tool. A flask framework written in Python language was used to create the tool, in addition to linking the SMS interface with Hi SMS Company.

Grading analysis. In the CS101 Course, we found the relationship between mead and vinyl degrees Using the Association rule algorithm As in Figure 2.

In the face-to-face course of term 371 and 372 (term 371 refers to the semester ID that the course conducted in. Also, 372 refers to the semester id that the course was conducted in at Qassim university).

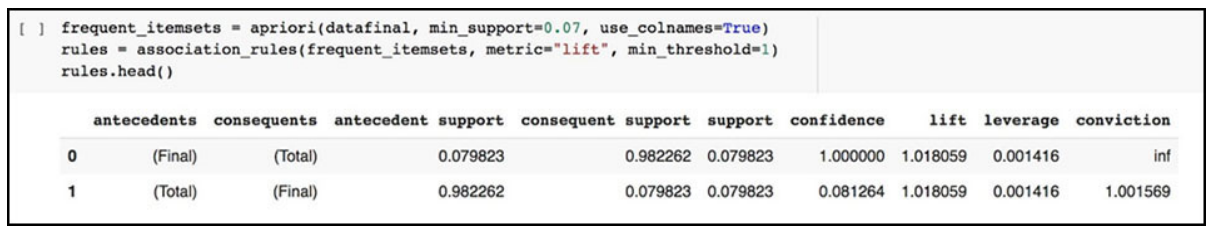

Fig. 2. The history of social media network user

In finding relationships, we keep repeating the confidence process and lift until we get the lowest value measurement of independence, so we have rules with high lift and low confidence. In the online course of term 411 and 412 as in Figure 3, (411 refers to the semester ID that the course conducted in. Also, 412 refers to the semester id that the course was conducted in at Qassim university).

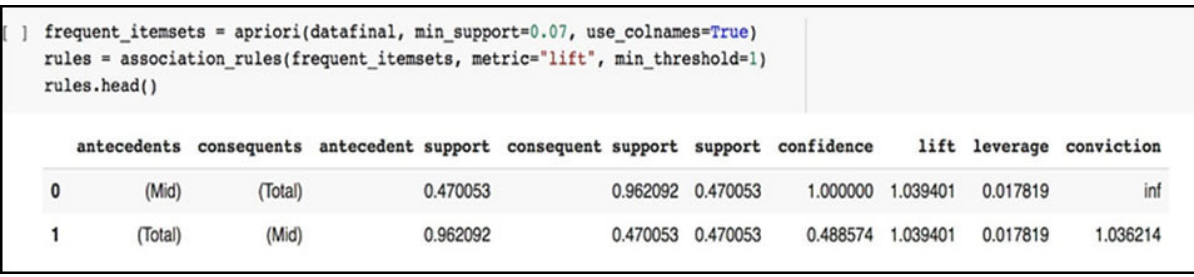

Fig. 3. The result of association rule of online course of term 411 and 412

In finding relationships, we keep repeating the confidence process and lift until we get the lowest value measurement of independence So that has rules with high lift and low confidence. 
The output of the independent t-test in SPSS statistics. Figure 4 provides useful descriptive statistics for the two groups that you compared, including the mean and standard deviation. In Figure 4, there was a significant difference in the score for online study, so that it shows $(\mathrm{M}=63.11, \mathrm{SD}=38.475)$ compared to face to face study that shows $(\mathrm{M}=58.57, \mathrm{SD}=36.646)$ where conditions $\mathrm{t}=(4.926)$ and $\mathrm{p}=.000$.

Group Statistics

\begin{tabular}{|ll|l|l|l|l|}
\hline & & & & $\begin{array}{l}\text { Std. Error } \\
\text { Mean }\end{array}$ \\
\hline V1 & online & 1801 & 63.11 & 38.475 & .907 \\
& faceToFace & 617 & 58.57 & 36.646 & 1.475 \\
\hline
\end{tabular}

Fig. 4. The SPSS results

At the end, students' grades in online education are better than face to face, and this enhances online education and works to improve the system to increase the efficiency more and more.

SMS tool. Aims to ensure that messages are delivered and easy to use for all university students and employees.

\section{Experimental}

Implementing of the Apriori algorithm. We use python language (scripts) in google collaboration to gain the best result in the implementation duo to the GPU (Graphical Processing Unit), the implementation steps to implement the algorithm comprise the following steps:

1. Import necessary library from python library as in Figure 5.

D 1 import numpy as np

2 import pandas as pd

3 import io

4 from mlxtend.frequent_patterns import apriori, association_rules

Fig. 5. Import python library

2. Import xlsx using Google Collab import file, as in Figure 6.

3. Data Preprocessing to clean and normalize the dataset/data preparation.

In this step, we need to prepare the dataset to be used in the python script. As shown in Figure 7 and Figure 8. First, we need to put a dataset called google collab in a data frame from panda's library. Second, we need to show the dataset to visualize data. Third, we need to clarify the column's name of our data set. The second and third steps show in Figure 9. 


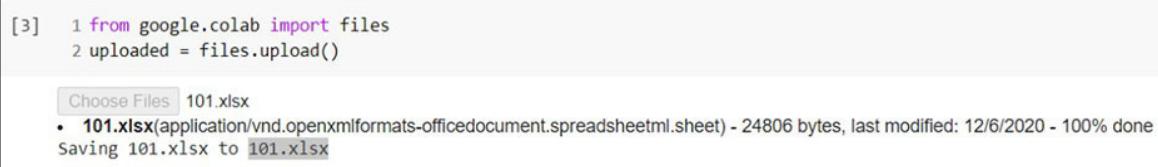

Fig. 6. All file using google collab

- 1 data $=$ io.BytesIo(uploaded['101.xlsx'])

$2 \mathrm{f}=$ pd.read_excel(data , sheet_name = 'ee')

$3 f \cdot \operatorname{head}()$

Fig. 7. Show this step procedure

\begin{tabular}{|crrrrr|}
\hline $\mathrm{C}$ & & Mid & Final & Total & Type \\
\cline { 2 - 5 } & $\mathbf{0}$ & 30.0 & 30.0 & 60.0 & 1 \\
$\mathbf{1}$ & 30.0 & 45.0 & 75.0 & 1 \\
$\mathbf{2}$ & $\mathrm{NaN}$ & $\mathrm{NaN}$ & $\mathrm{NaN}$ & 1 \\
$\mathbf{3}$ & 40.0 & 55.0 & 95.0 & 1 \\
4 & 30.0 & 35.0 & 65.0 & 1 \\
& & & & \\
\hline
\end{tabular}

Fig. 8. Data frame

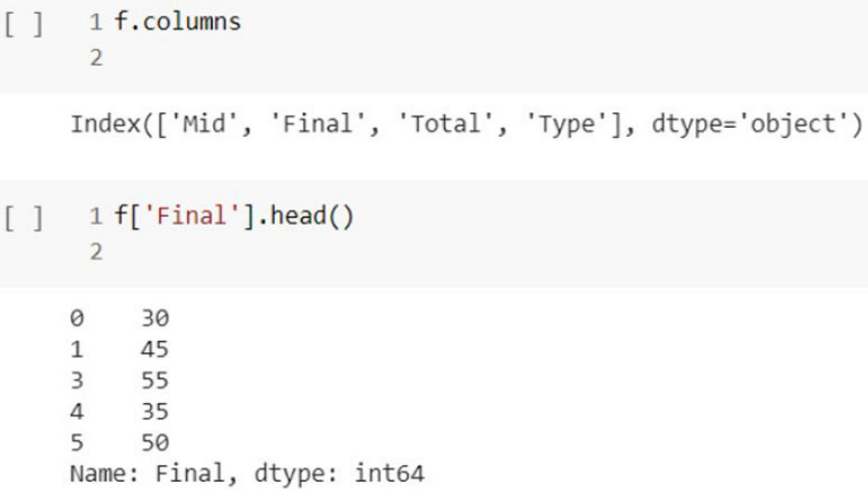

Fig. 9. How columns name and visualize data 
4. Data cleaning: This step considers an important step where our dataset has many nulls value and missing values. So, implementing our Apriori algorithm in the right implementation, we need to clear all the missing and null values. We use dropna () method from pandas to ensure the absence of missing and null values. Figure 10 illustrates the implementation of this step.

( $1 \mathrm{f}=\mathrm{f}_{\text {.dropna(how }}$ ' $^{\text {any }}$ ' $^{\text {, axis }}=0$ ) $\mid$

Fig. 10. Data cleaning

5. Data preprocessing: Data preprocessing step considers the most important step in data mining. Duo to this important we ensure handling the dataset at the right use. First, we change the type of the values in the dataset from float to integer. As illustrated in the Figure 11. Second, we normalize the dataset to zero and one depending on the success and fail in the Total column using python check over 50 consider a one less than 50 consider a zero. The code used for this step's implementation represent in Figure 12.

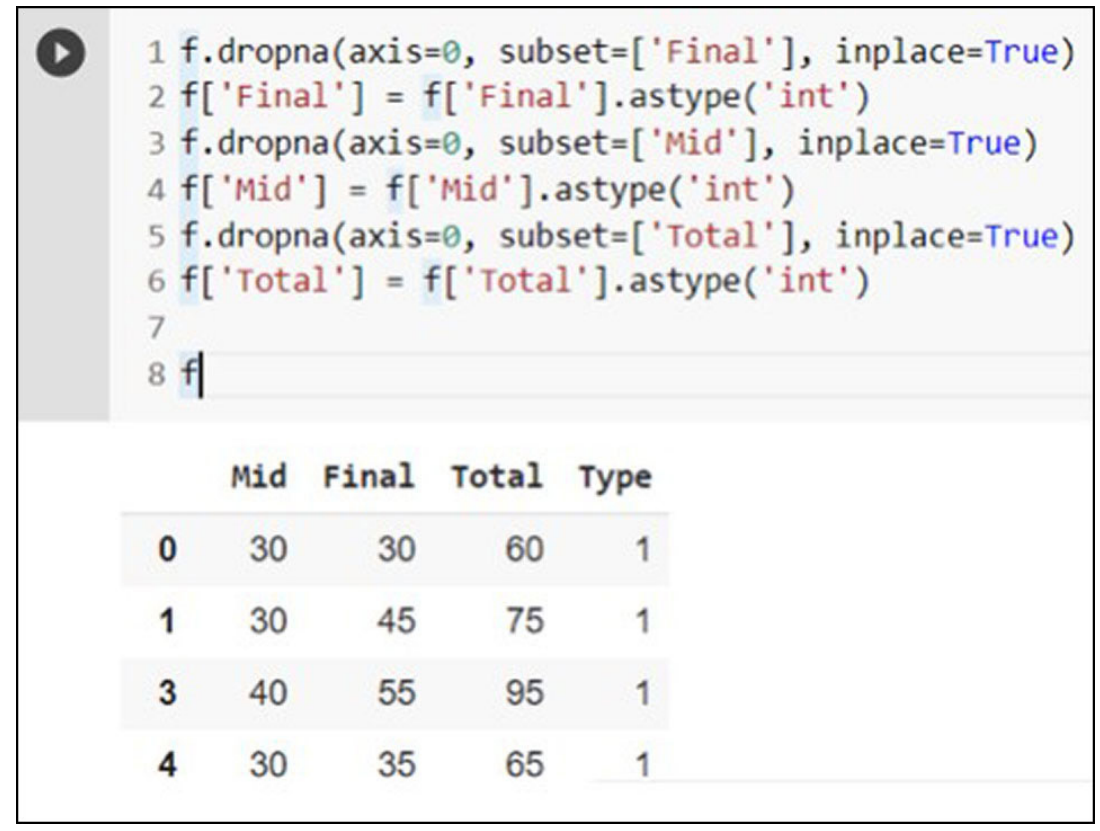

Fig. 11. Change values type to integer 


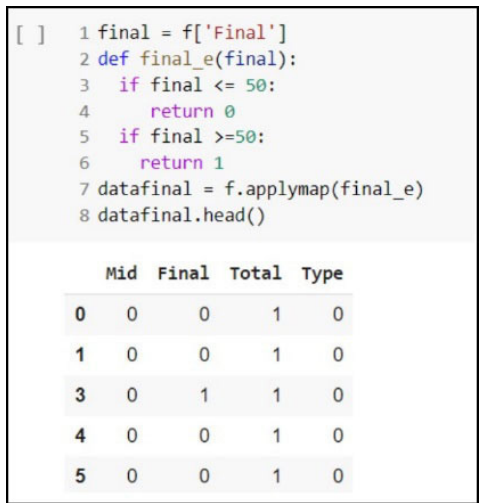

Fig. 12. Implementations represent

6. Implement aprior from (mlxtend.frequent-patterns): In this phase we implement the Apriori algorithm from the mlxtend library. The scripts represent the implementation is showing in Figure 13. Also, we implement the association rules using the same library (mlxtend) to illustrate the implementation of the script Figure 14 is represented.

] 1 frequent_itemsets $=$ apriori (datafinal, min_support $=0.07$, use_colnames $=$ True) 2 rules $=$ association_rules $($ frequent_itemsets, metric $=" 1$ ift", min_threshold $=1$ ) 3 rules.head()

Fig. 13. Apriori algorithm

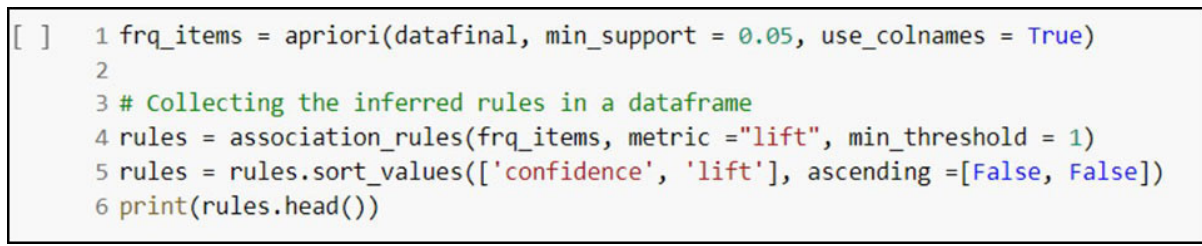

Fig. 14. Association rules

Implementing independent t-test. The independent-samples of t-test (or independent $\mathrm{t}$-test, for short) compares the means between two unrelated groups on the same continuous dependent variable [16].

In our report, we compare the means between two unrelated groups. The online group and face-to-face group and compare the result to conclude the relation and feature. Also, we test the following Assumption: [17].

Assumptions. Before we choose to analyze any data using an independent t-test, six assumptions must be done. This procedure which ensures that data is appropriate to use an independent t-test occurs if our data passes six assumptions that are required for an independent test to get a valid result. Checking these six expectations just adds extra time to our analysis. However, we use SPSS Statistics and think a little more about our data, which is not a difficult task $[18,19]$. 
Assumption 1. Our predictor variables must be evaluated on a scale of one to ten (i.e., it is measured at the interval or ratio level). This criterion is met by variables such as revision time (measured in hours), weight (measured in $\mathrm{kg}$ ), academic performances (measured from 0 to 100), intelligence (measured using an IQ score), and so on. During the independent between each data set, our data meet this assumption.

Assumption 2. Our independent variable should consist of two categories, independent groups. Our data sets meet this assumption duo to the two main categorical online and face to face.

Assumption 3. We should have observational independence, which indicates that there should be no correlation between the observations in each group or between the groups themselves. Our variables are independent that were gotten from separated groups.

Assumption 4. There should be no notable outliers. Outliers are simply individual data points within data that don't really follow the expected pattern (for example, in a study of 100 students' IQ scores, where the average score was 108 only with a small variation among students, one student had a scoring rate of 156 , that is very unexpected and may even place her in the best $1 \%$ of IQ scores global level). The problem with outliers is that they can have a negative outcome on the independent t-test, reducing the validity of results. Fortunately, when using SPSS Statistics to run an independent t-test on our data, we can easily detect possible outliers. In our enhanced independent t-test guide, we: balance the degree of student between zero and 100 so there are not any outliers.

Assumption 5. For each group of the independent variable, our dependent variable should be approximately normally distributed. We discuss more about independent t-test requesting only nearly data samples since it is quite strong to infractions of normality, which means that this assumption can be violated slightly as well as provide accurate result.

Assumption 6. There are some requirements for variance homogeneity. We can test this assumption in SPSS Statistics using Levine's test for homogeneity of variances. Our data sets achieve this assumption also.

Test Procedure in SPSS Statistics. The steps to execute are as follow: Click Analyze Compare Means Independent-Samples T Test. On the top menu. Figure 15 shows the choose test type.

\begin{tabular}{|l|l|l|l|l|l|l|l|}
\hline & Reports & & \\
\hline \\
\hline
\end{tabular}

Fig. 15. Choose the test type 
In the following figure we will set the variables of the test from the variables view. Figure 16 show the changes. It will be presented with the Independent-Samples T Test dialogue box, as shown below in Figure 17:

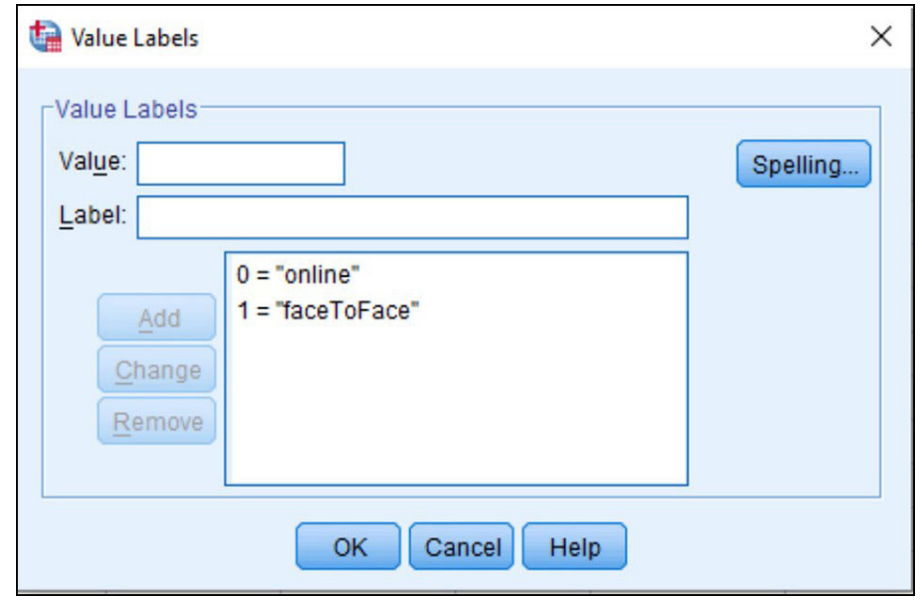

Fig. 16. Setting the variables

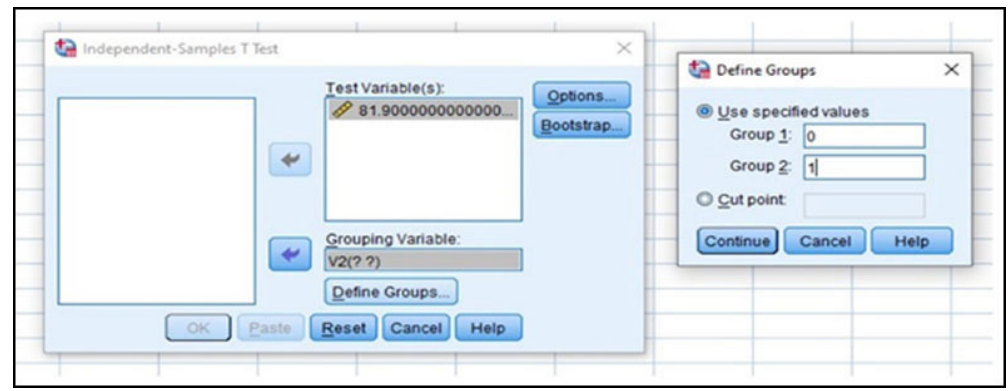

Fig. 17. Setting value

Implementing SMS tool. The interface of blackboard system was created to increase the efficiency and effectiveness of the system [20, 21]. However, we want to create additional tool that targets the faculty, students, and employees at Qassim University. Our implemented tool contains three interfaces, the first one, an interface for adding a 
new user that includes (first name, last name, date of birth, email, mobile number, user type, college name). Second, the interface for uploading (CSV) files containing user data to the database directly. Third, the SMS sending interface enables the sender to specify the person to whom the message is sent.

Moreover, we implemented SMS tool, using the Flask framework through its depended on the Hi SMS company services to offer a web interface that enables the user to send and receive messages. However, data (students' information) was first collected through a questionnaire to access personal data (which includes their phone number) for each student, teacher, and employee, and then insert the data into the interface of the SMS tool.

The main screen of the SMS Tool interface shown in Figure 18 contains three interfaces:- The first interface to add a new user, the second interface to download files of type (CSV), the third interface to display the users added in the database and send messages.

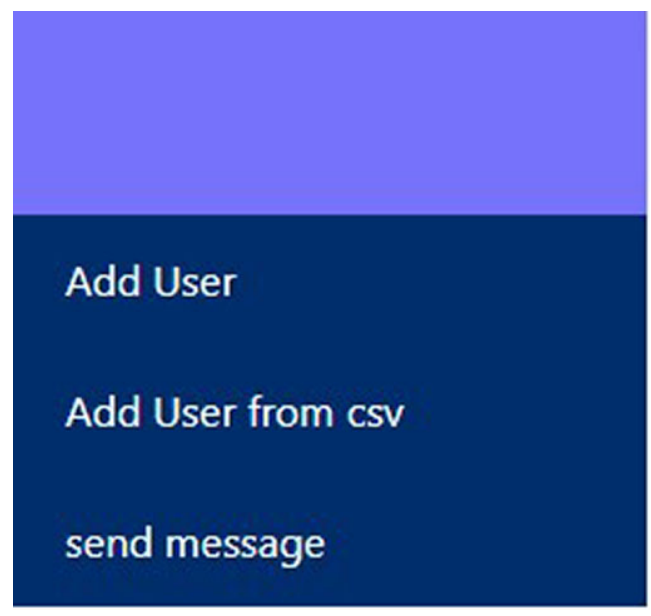

Fig. 18. The main interface

Add user interface. From the interface in Figure 19, we can add a new user by filling his information (first name, last name, email, mobile number, college, student field, date of birth). 


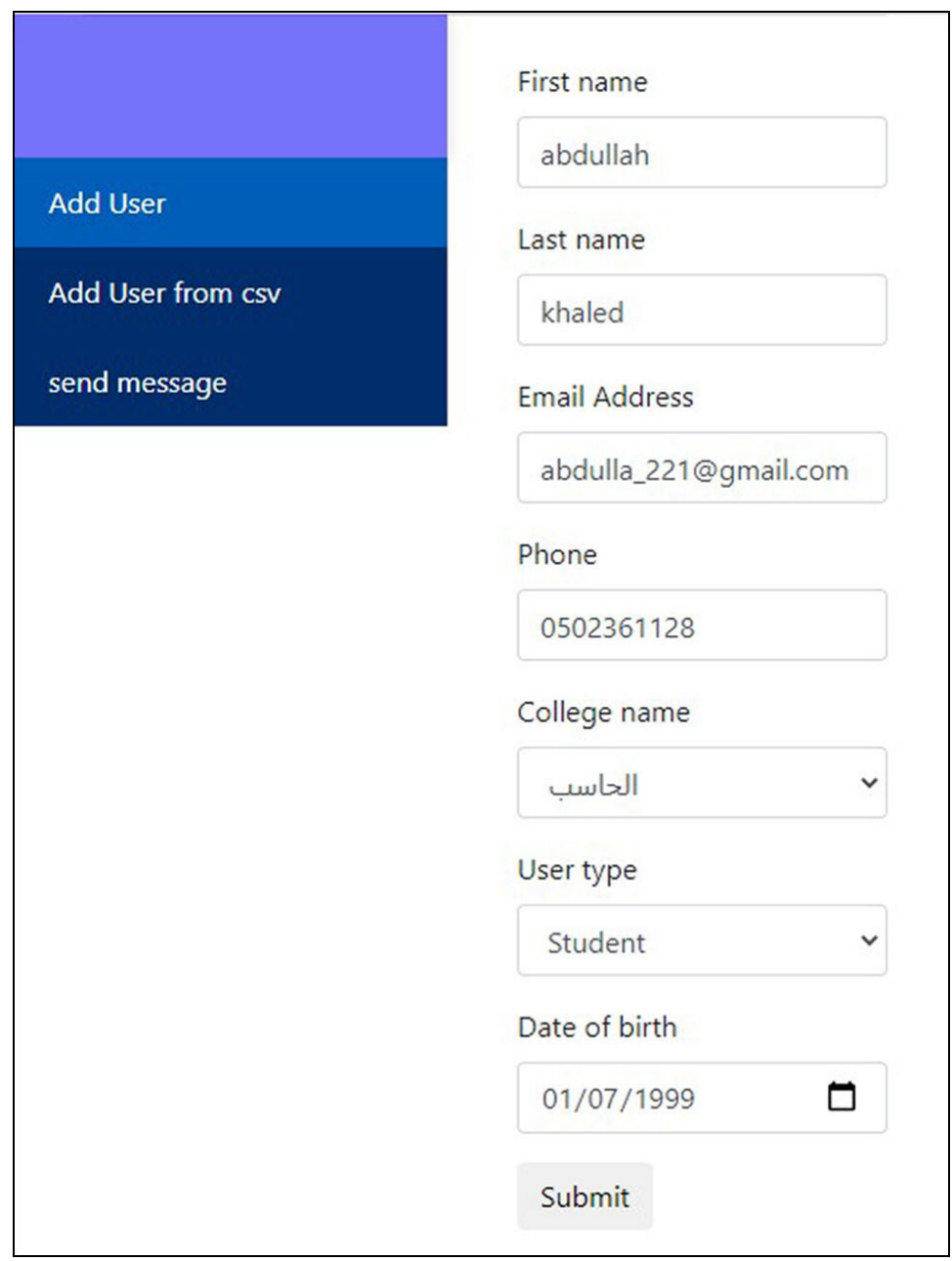

Fig. 19. Example for add user interface

Add user from csv. The Figure 20 shows interface that allows us to upload a (CSV) file directly to the database.

Send message interface. This interface which is shown in Figure 21 includes all the data in the database added in the interface. Through this interface, we can send messages.

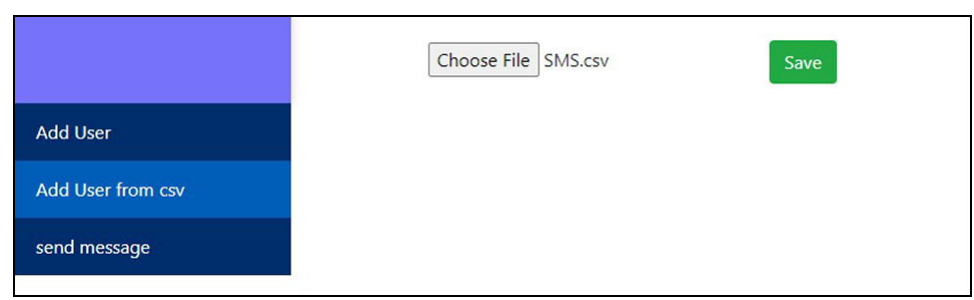

Fig. 20. Add user from csv 


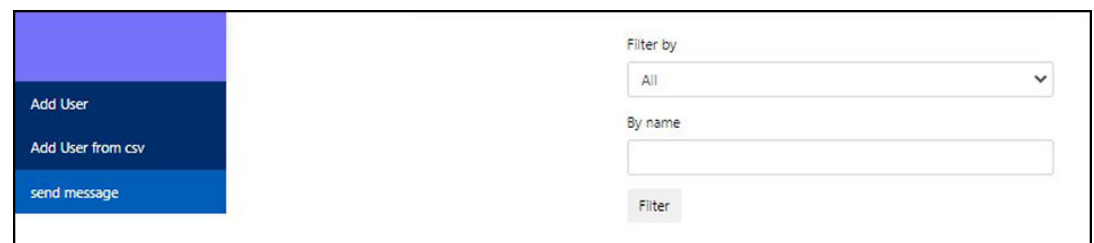

Fig. 21. Send message interface

Search by field type. Figure 22 shows how the sender can search by user type (students, teachers, employees).

Search by name. Figure 23 shows how the sender search by name.

Send a message (SMS). Figure 24 shows that the sender can send messages to specific users or to everyone.

Examples of Send Messages (SMS) Interface are shown in Figure 25.

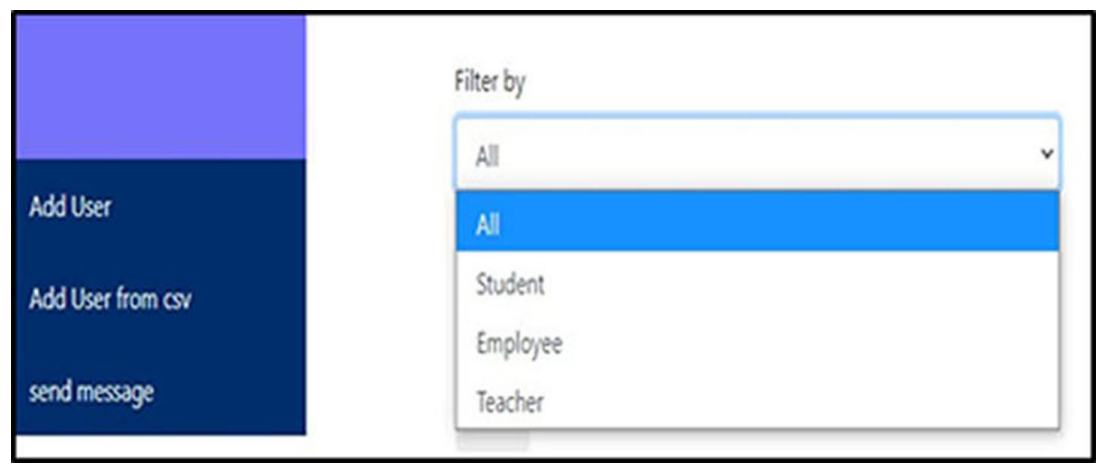

Fig. 22. Search by field type

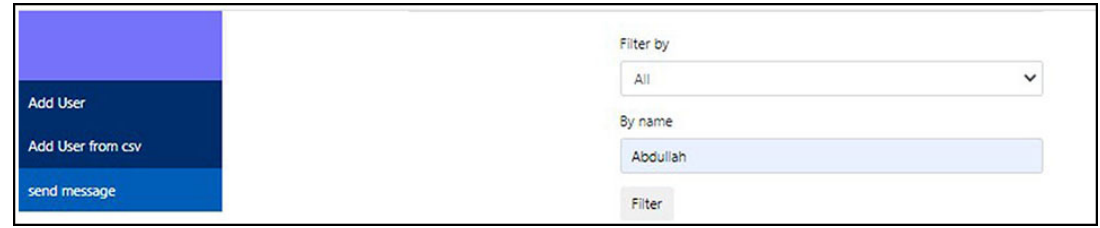

Fig. 23. Search by name

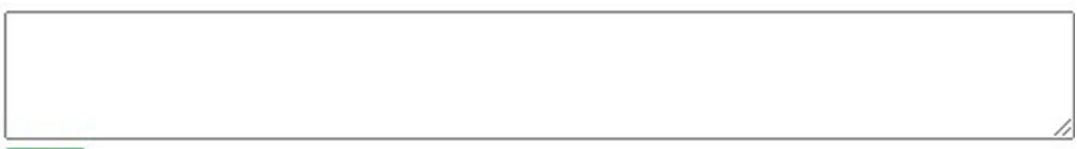

send

Fig. 24. Send a message (SMS) 


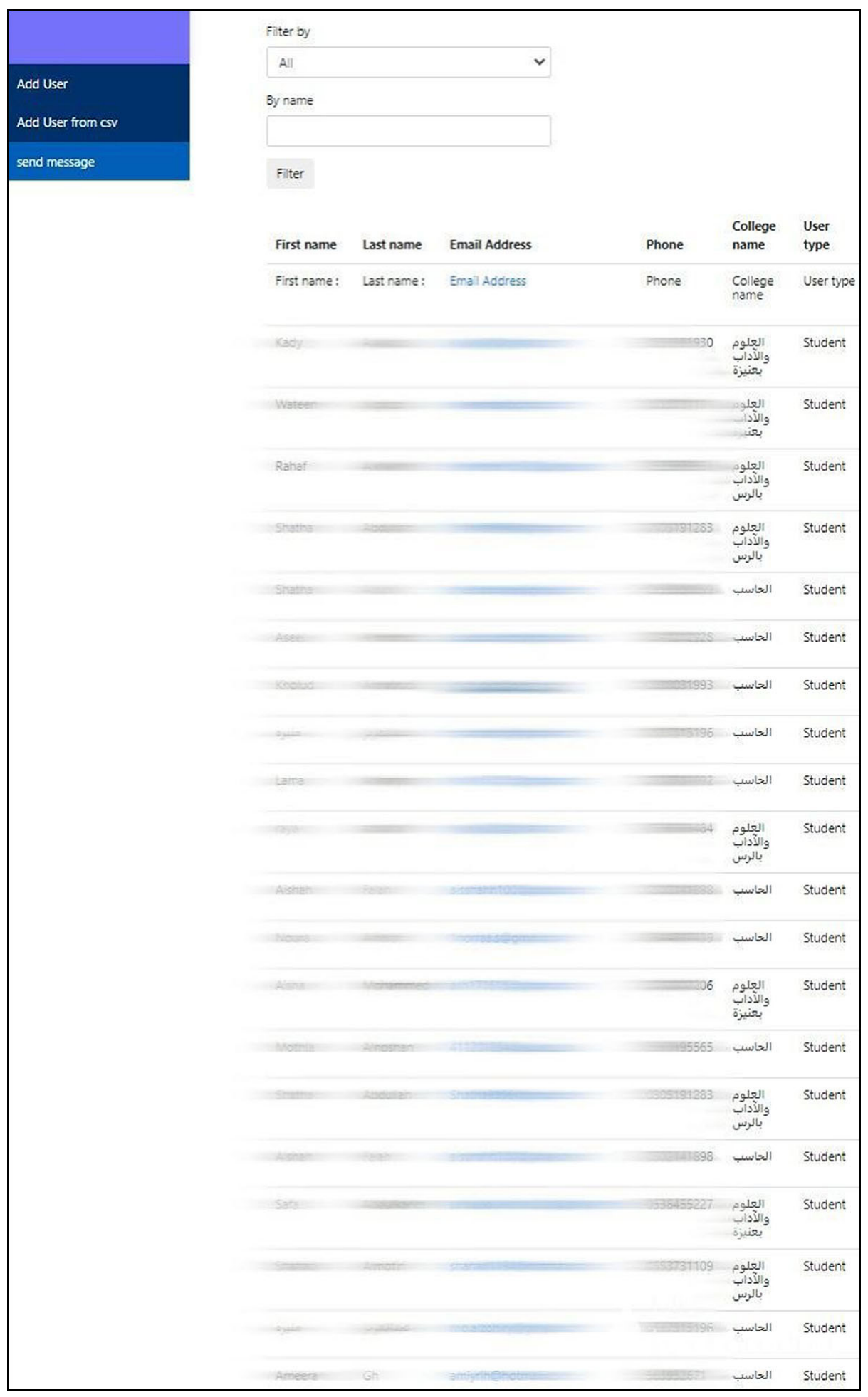

Fig. 25. Example of send messages (SMS) interface 


\section{Conclusion}

In this research, we analyzed and compared a set of student data (grades) of online and face-to-face courses. However, we developed an SMS tool that can contribute to improving the ability to send messages and notifications to all students and promptly.

\section{$7 \quad$ References}

[1] Kumar Basak, S., Wotto, M., and Belanger, P. (2018). E-learning, M-learning and D-learning: Conceptual definition and comparative analysis. E-learning and Digital Media, 15(4): 191-216. https://doi.org/10.1177/2042753018785180

[2] Mishra, P., Singh, U., Pandey, C. M., Mishra, P., and Pandey, G. (2019). Application of student's t-test, analysis of variance, and covariance. Annals of cardiac Anaesthesia, 22(4): 407. https://doi.org/10.4103/aca.ACA 9419

[3] Li, Y., Zhang, H., and Liu, S. (2020). Applying data mining techniques with data of campus card system. In IOP Conference Series: Materials Science and Engineering (vol. 715, no. 1, p. 012021). IOP Publishing. https://doi.org/10.1088/1757-899X/715/1/012021

[4] Cheung, D. W., Ng, V. T., Fu, A. W., and Fu, Y. (1996). Efficient mining of association rules in distributed databases. IEEE transactions on Knowledge and Data Engineering, 8(6): 911-922. https://doi.org/10.1109/69.553158

[5] Vassell, C., Amin, N., and Patel, D. (2006, August). Mobile learning: using SMS to enhance education provision. In 7th Annual Conference of the Subject Centre for Information and Computer Sciences, 2006, pp. 29-31.

[6] Al-Malki, N., AbdulKarim, A. H., and Alallah, F. S. (2015). Teaching staff's and students' initial perceptions and satisfaction with teaching and learning via the Blackboard LMS. International Journal of Advanced Corporate Learning, 8(2): 37. https://doi.org/10.3991/ ijac.v8i2.4749

[7] Almatrafi, O., Islam, K., Johri, A., Nagappan, K., and Modanlu, A. (2015, June). An Empirical Study of Face-to-Face and Distance Learning Sections of a Core Telecommunication course. In 2015 ASEE Annual Conference and Exposition, pp. 26-182.

[8] Naveed, Q. N., Qureshi, M. R. N., Tairan, N., Mohammad, A., Shaikh, A., Alsayed, A. O., and Alotaibi, F. M. (2020). Evaluating critical success factors in implementing E-learning system using multi-criteria decision-making. Plos one, 15(5), e0231465. https://doi. org/10.1371/journal.pone.0231465

[9] Osman, I., Nasir, M., and Alzoubi, R. (2017). Blackboard Usage: An Investigative Study among CCSE Female Faculty Staff and Students at University of Hail. Journal of Economic and Management Perspectives, 11(2): 508-515.

[10] Hamad, M. M. (2017). Pros and Cons of Using Blackboard Collaborate for Blended Learning on Students' Learning Outcomes. Higher Education Studies, 7(2): 7-16. https://doi. org $/ 10.5539 /$ hes.v7n2p7

[11] Naveed, Q. N., Qureshi, M. R. N. M., Shaikh, A., Alsayed, A. O., Sanober, S., and Mohiuddin, K. (2019). Evaluating and ranking cloud-based e-learning critical success factors (CSFs) using combinatorial approach. IEEE Access, 7, 157145-157157. https://doi. org/10.1109/ACCESS.2019.2949044

[12] Muniasamy, A., and Alasiry, A. (2020). Deep Learning: The Impact on Future eLearning. International Journal of Emerging Technologies in Learning (iJET), 15(1): 188-199. https:// doi.org/10.3991/ijet.v15i01.11435 
[13] Baig, M., Gazzaz, Z. J., and Farouq, M. (2020). Blended Learning: The impact of blackboard formative assessment on the final marks and students' perception of its effectiveness. Pakistan Journal of Medical Sciences, 36(3): 327. https://doi.org/10.12669/pjms.36.3.1925

[14] Boukil, S., Biniz, M., El Adnani, F., Cherrat, L., and El Moutaouakkil, A. E. (2018). Arabic text classification using deep learning technics. International Journal of Grid and Distributed Computing, 11(9): 103-114. https://doi.org/10.14257/ijgdc.2018.11.9.09

[15] Alkhatib, A. A. S., and Jaradat, S. A. (2021). The Impact of Blended Learning using the Ideas Box on the Motivation for Learning Among Non-formal Syrian Female Refugee Students in Jordan. International Journal of Interactive Mobile Technologies (iJIM), 15(11): 81-95. https://doi.org/10.3991/ijim.v15i11.21961

[16] Investopedia. (2019) Types of t-test. Accessed: 31.7.2021. [Online]. Available: https://www. investopedia.com/terms/t/t-test.asp

[17] Baig, M., Gazzaz, Z. J., and Farouq, M. (2020). Blended Learning: The impact of blackboard formative assessment on the final marks and students' perception of its effectiveness. Pakistan journal of medical sciences, 36(3): 327. https://doi.org/10.12669/pjms.36.3.1925

[18] Tin, T. G., Atan, N. A., Said, M. N. H. B. M., Ali, M. F., Mohd, S., and Abd Hamid, M. Z. (2018). Integrating Animations in Chinese Character Writing Based on Cognitive Theory of Multimedia Learning to Promote Students' Writing Skills. International Journal of Interactive Mobile Technologies (iJIM), 12(7): 97-111. https://doi.org/10.3991/ijim.v12i7.9671

[19] El-Sofany, H. F., and El-Seoud, S. A. (2009). Towards the Development of an M-Learning System: A New Stage to Enhance Higher Education. International Journal of Interactive Mobile Technologies (iJIM), 3(3): 4-9. https://doi.org/10.3991/ijim.v3i3.719

[20] Muhammad, A., Shaikh, A., Naveed, Q. N., \& Qureshi, M. R. N. (2020). Factors affecting academic integrity in E-learning of Saudi Arabian Universities. An investigation using Delphi and AHP. IEEE Access, 8, 16259-16268. https://doi.org/10.1109/ACCESS.2020.2967499

[21] Aslam, F. A., Mohammed, H. N., Mohd, J. M., Gulamgaus, M. A., and Lok, P. (2015). Efficient way of web development using python and flask. International Journal of Advanced Research in Computer Science, 6(2): 54-57.

\section{Authors}

Dalia Alshmasi, received the BSc. degree in information technology from Qassim University, Mulayda, Qassim, Saudi Arabia. (Email: 362208371@qu.edu.sa).

Jawaher Alharbi, received the BSc. degree in information technology from Qassim University, Mulayda, Qassim, Saudi Arabia. (Email: 351202089@qu.edu.sa).

Nada Alhothly, is received the BSc. degree in computer science from Qassim University, Mulayda, Qassim, Saudi Arabis, the master's degree in computer science with spatialization in E-Learning from The University of Montana, Missoula, Montana, USA, in 2015. Since 2009, she has been on the faculty of Qassim University. She is manly engaged in the research of computer science. (Email: nhthly@qu.edu.sa)

Article submitted 2021-09-18. Resubmitted 2021-10-19. Final acceptance 2021-10-21. Final version published as submitted by the authors. 